\title{
3D Printing in Pre-Engineering and Physics Courses
}

\author{
Redahegn Sileshi ${ }^{1}$, JB Sharma ${ }^{2}$, Hoang Pham ${ }^{3}$, Alfred Walters ${ }^{4}$, \\ Forrest Ables $^{5}$, and Brandon Persaud ${ }^{6}$ \\ Associate Professor of Engineering ${ }^{1}$ \\ Professor and Eminent Scholar Physics and Remote Sensing ${ }^{2}$ \\ Assistant Professor of Physics ${ }^{3}$ \\ Associate Professor of Physics ${ }^{4}$ \\ Undergraduate Researcher and Digital Fabrication Lab Supervisor ${ }^{5,6}$ \\ University of North Georgia, Oakwood, Georgia, USA
}

\begin{abstract}
A strong emphasis on active learning, integration of hands-on activities, and design projects into course curriculum have been shown to significantly enhance and deepen understanding of concepts in the course. Many higher education institutions across the United States are increasingly incorporating three-dimensional (3D) printing technology into their course curriculum to nurture their students' creativity. 3D printing is a manufacturing method in which solid 3D objects are printed layer by layer from raw materials. This article presents our efforts to integrate 3D printing technology into our pre-engineering and physics courses at University of North Georgia (UNG) Gainesville campus. UNG is a regional multi-campus university and premier senior military college positioned in the fastest-growing region of Georgia, USA. Pre-engineering and physics students from the UNG Gainesville campus took part in a semester long design project that utilized 3D printing technologies. Most of the students who took part in this design projects had no or limited experience with both Computer-Aided Design (CAD) modeling as well as 3D printing technology. But despite having limited prior experience, all student indicated a relatively high interest in learning more about 3D printing technology.
\end{abstract}

Keywords: CAD Modelling, Design Projects, 3D Printing.

\section{INTRODUCTION}

Exposing undergraduate students early on to hands on projects have been proven to be an effective means to prepare them to be engaged learners [1][2]. Design is an essential element of engineering education; and research has recognized the value of using design project-based learning experiences to teach freshmen engineering students about design process [3]. Design experiences can be facilitated using 3D printing technologies [2][4]. 3D printers may heighten students' intellectual curiosity, thus improving students' chances of success in engineering [2]. 3D printing is quickly becoming the fastest and most affordable way to revolutionize STEM (Science, Technology, Engineering and Mathematics) education by allowing for technology driven iterative design experiences [5]. 3D printing technology is revolutionizing the design and fabrication process of products by increasing the speed and efficiency in which complex 3D objects can be created [6][7].

Giving access to 3D printers enables students and turns them into thinkers, designers and builders. 3D printing technology is an effective tool to allow students to physically see the changes they make to a design concept. The use of 3D printers was an effective tool for a graphics design course in which students were asked to recreate an object from a 3D printer using Autodesk's 3D CAD design software [4]. Several studies have indicated the positive impacts of 3D printing on STEM education for design-prototype and manufacture projects [8][9][10].

It was found that there was a highly positive impact of the students' perceived value of using a 3D printer in the classroom, which increased the students' academic performance when its use was closely tied to the class content [10]. This exposes students to the same cutting-edge technologies they will encounter in their careers. The Fused Deposition Modeling (FDM) 3D printers are the most used 3D-printing technologies by commercial numbers now and the qualities of the technology makes it popular especially in academic environments [11]. Different types of materials can be used for 3D printing, such as ABS (acrylonitrile butadiene styrene) plastic, PLA (polylactic acid), nylon, epoxy resins, silver, steel, 


\section{International Advanced Research Journal in Science, Engineering and Technology}

Vol. 7, Issue 9, September 2020

\section{DOI 10.17148/IARJSET.2020.7910}

wax etc. Most common plastics for 3D printing are ABS and PLA. 3D printers extrude the thermoplastics polymer ABS or PLA as print materials and create a 3D object by extruding many fine layers over one another until the object is complete [7]. While ABS and PLA can create functional objects, for some applications plastic parts are just not strong enough.

\section{METHODS AND MATERIALS}

The Physics department in collaboration with the Art department in the University of North Georgia (UNG) Gainesville campus opened a Digital Fabrication Laboratory (DFL). The goals are to assist faculty in using 3D printing technology and to develop the curriculum. The Digital Fabrication Laboratory (DFL) is currently equipped with variety of 3D printer types, such as Afinia H800+, Makerbot Replicator 2 and $5^{\text {th }}$ Generation, Hyrel 3D, FormLabs Form 2, Lulzbot Taz 5 3D, Powder based 3D printer, 3D scanners, and slicing software for 3D printers (Fig.1). Currently Physics, Pre-engineering, and Art students have been direct beneficiaries of the DFL. Students from these departments are able to develop and 3D print models personally designed for class projects, design groups, research or personal use. The DFL is open to anyone on campus to use and test the 3D printing technology. The authors strongly believe that their experience with 3D printing technology will be useful to other pre-engineering programs seeking to implement this technology into their course curriculum.

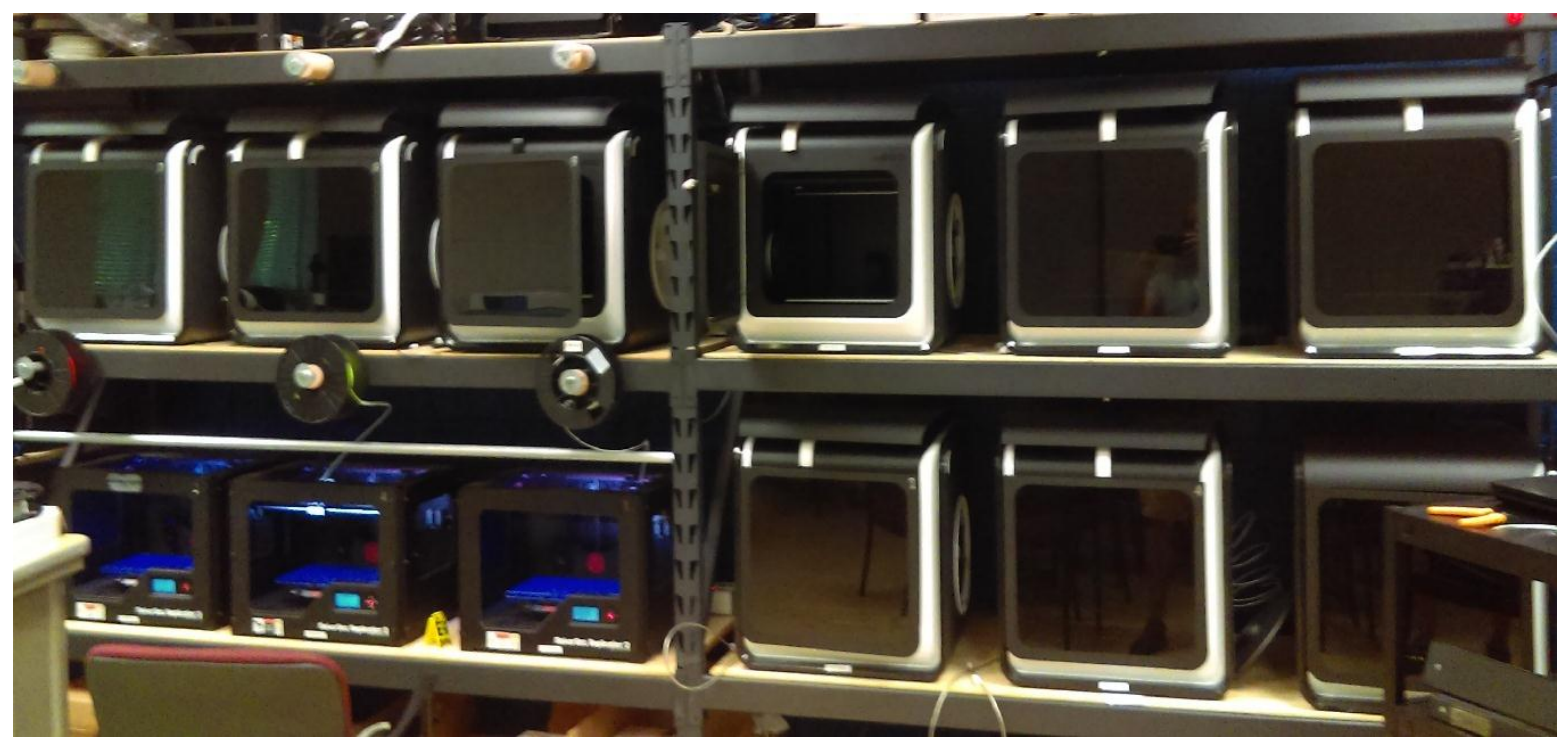

Fig. 1. Examples of 3D printer types in our Digital Fabrication Laboratory

A formal introduction to the Digital Fabrication Laboratory (DFL)'s 3D printers is presented as a part of Computer-Aided Design (CAD) topics in the pre-engineering courses, Introduction to Engineering and Design and Engineering Graphics Design. Students were exposed to the 3D printing process through a demo given by DFL teaching assistants (TAs). The demos gave rudimentary training on operating the printers with the goal that students, with the guidance of TAs, quickly will learn to perform their own printing independently. The DFL is open 3 days a week for about 4-6 hours and is staffed by TAs and students' trainees. As part of a semester group project, student project teams created CAD models of their design using Autodesk's CAD software and 3D printed them with the assistance of the TAs. The CAD drawings have to be saved with the STLOUT (stereolithography) command. This command stores 3D solids and watertight meshes in a format that can be used with 3D printing. The 3D printing slicing software that creates layer by layer G-code (numerical control programming language that instructs machines how to move) files are open source software packages.

The 3D printing process flow chart (Fig. 2) helps students to separate all the necessary stages in order to perform the 3D print. First stage is to create a digital 3D model using CAD. The 3D model file is transferred to the slicing software that is used with the $3 \mathrm{D}$ printers. The printing itself takes place along with proper follow-up to the process. The last stage is to post-process the print and evaluate the result. 


\section{International Advanced Research Journal in Science, Engineering and Technology}

Vol. 7, Issue 9, September 2020

DOI 10.17148/IARJSET.2020.7910

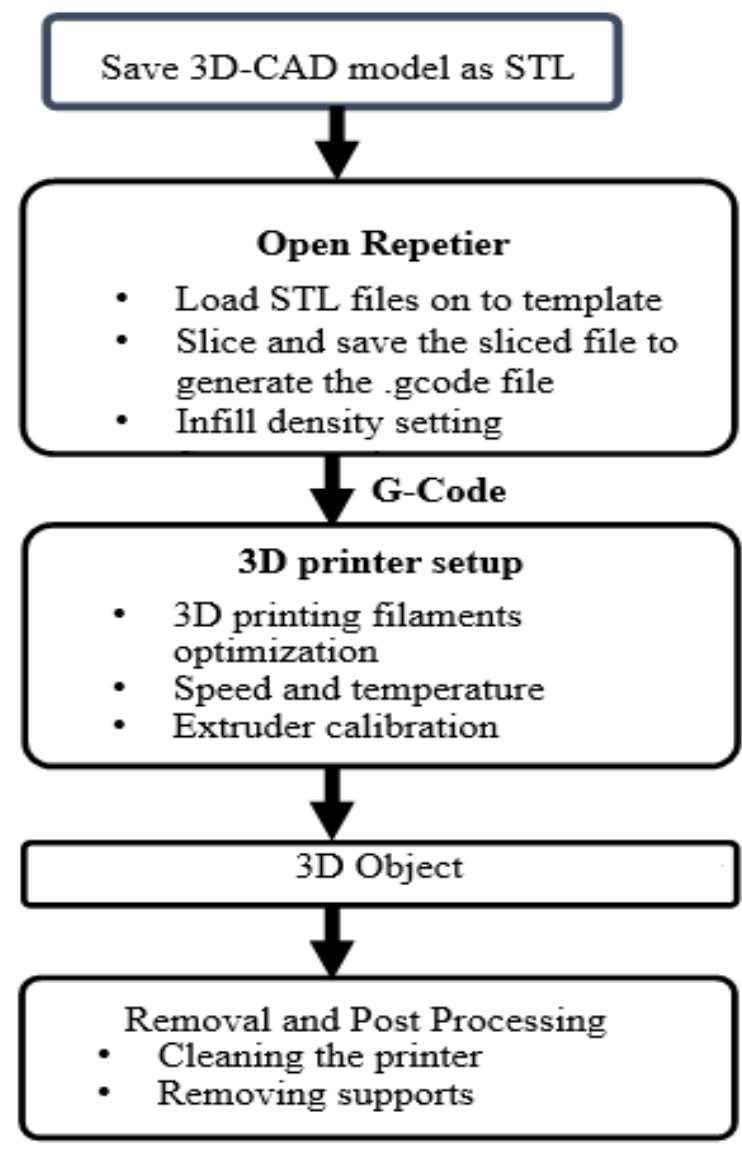

Fig. 2. 3D printing flow chart summary

\section{RESULTS AND DISCUSSIONS}

Students conceived and developed a semester-long design project from a computer design concept that was then 3D printed. Example of 3D printed parts from students group projects are summarized below (Fig.3-5). Students developed and designed a system, the 'Phenol-Board', for the UNG Gainesville's Chemistry department laboratories to help organize the glassware, increase space in the student drawers, and minimize glassware contact and breakage. The system is simple, cheap to produce, and reasonable sized in order to fit inside the laboratory drawers with the remaining space for miscellaneous items. This board will be utilized to help organize the student drawers by having several cutouts and grooves on the board intended for the various tools and glassware to fit in. The cutouts and grooves are tailored to fit the different beakers, test tubes, and Erlenmeyer flasks in the laboratory drawers. The first step taken in designing the PhenolBoard was to obtain some glassware for dimensioning. After all dimensions were recorded for the glassware, the students began the designing process with AUTOCAD. Since the largest surface area available by the 3D printers is $290 \mathrm{~mm}$ by $190 \mathrm{~mm}$, the design had to be sized accordingly. Thirty-two pieces of glassware can be placed on the board because that would fulfill each lab group with enough equipment to utilize in student's lab meetings.
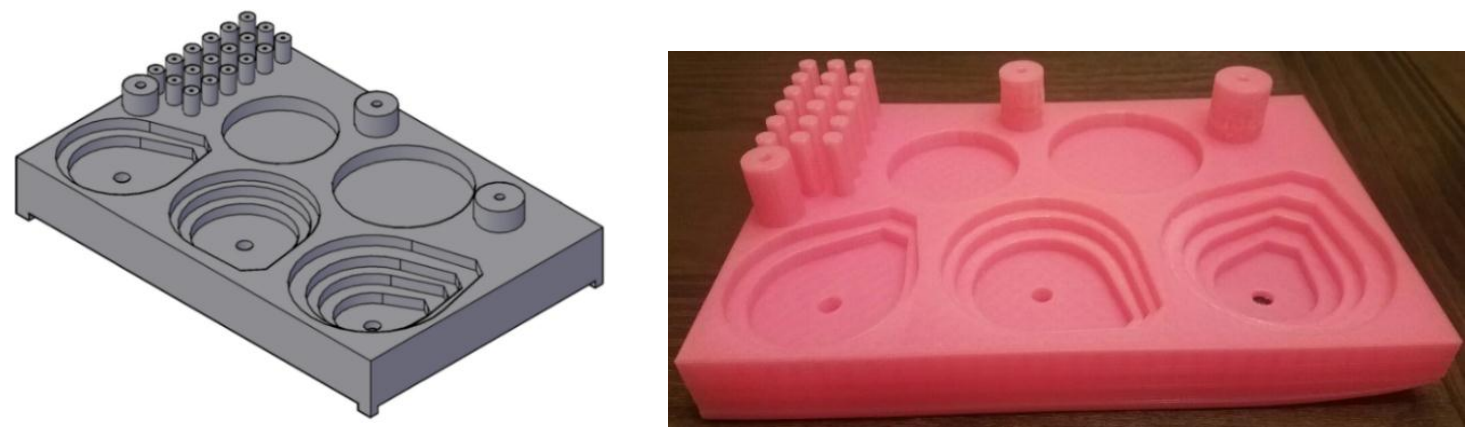

Fig. 3. 3D printed glassware holder. 


\section{International Advanced Research Journal in Science, Engineering and Technology}

Vol. 7, Issue 9, September 2020

\section{DOI 10.17148/IARJSET.2020.7910}

Whether one wants to cook, to access water, to open their shampoo, or to take many over the counter (OTC) medications, one may do so only through the operation of lids. Students created a cheap, simple jar opener (Fig. 4) that could be materialized in the comfort of a patients' home. A single moving component is included to simplify design and increase lifespan and durability of the final model. This led students to a countertop form factor with a motorized head sitting above the jar lid. This motor was to be the only moving component, resting in a body of 3D printed filament. With a single motor and access to 3D printing technology capabilities, students were able to assemble a working household appliance that would drastically improve the lives of elderly osteoarthritis patients around the world. Students created a universal cup holder for cars shown in Fig.5 below.

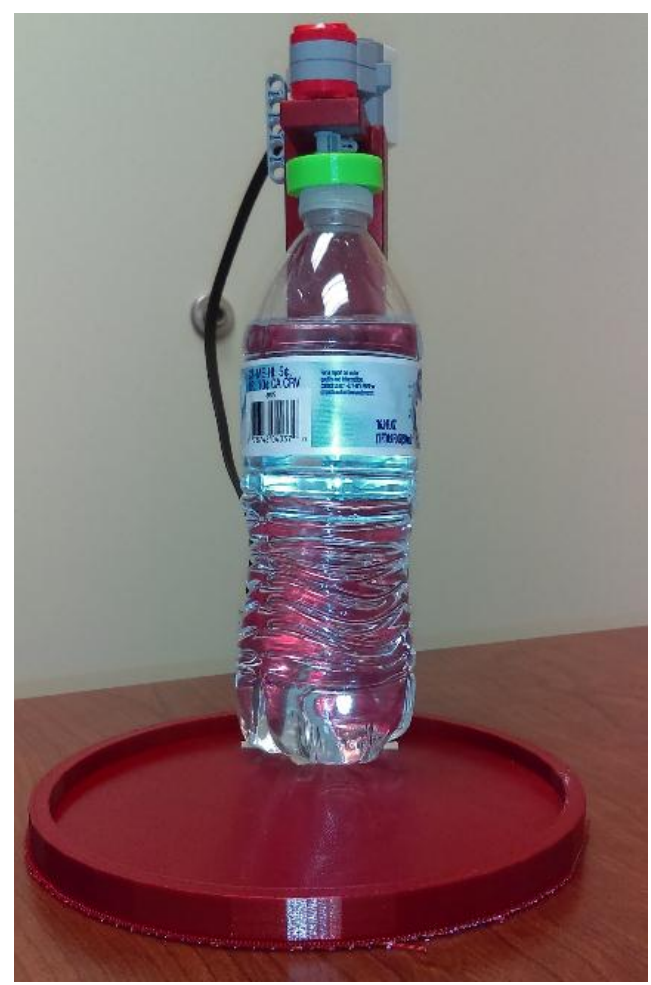

Fig. 4. Simple bottle opener.
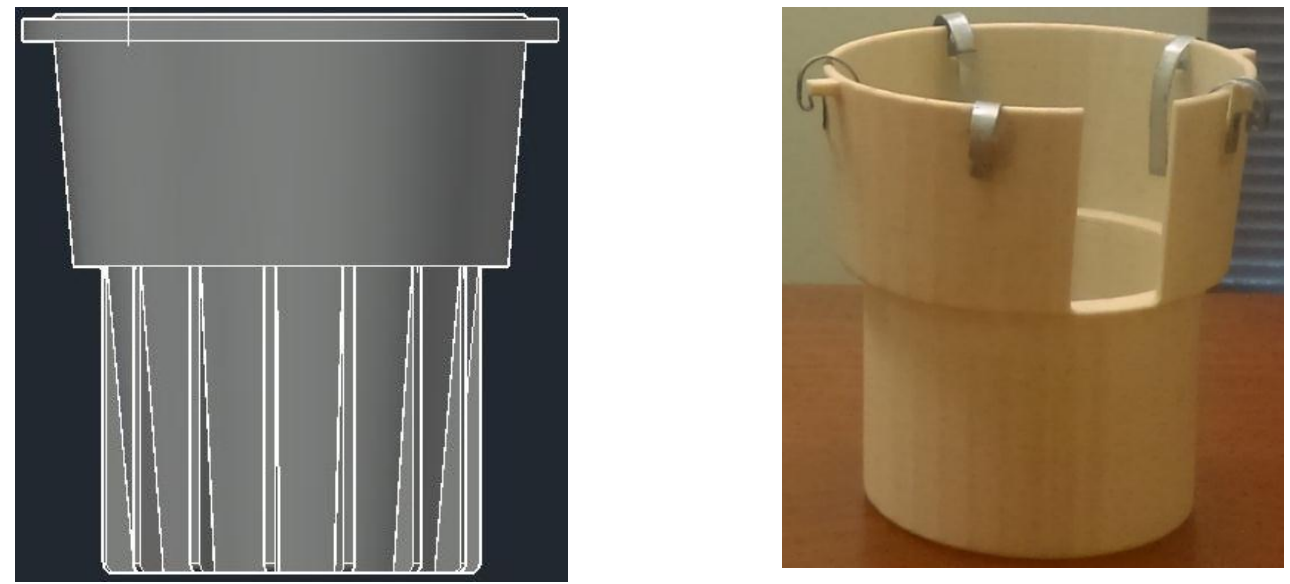

Fig. 5. Cup holder for cars.

Students designed a universal rotary table (Fig. 6) that will house up to four different medical exams. This will create an efficient workstation for technicians and a comfortable exam station for the patients. This design will minimize the time wasted between transition of exams, alleviate workload for technicians, and help patients with mobility complications. It is comprised of an actuator that will raise/lower the top of the table from 0.91 (3) to 1.22 (4) $\mathrm{m}$ (feet), four modules that will house each piece of equipment, a brake system to prevent the table from moving during patient examination, an electrical control panel, and a router for connectivity to any EMR (electronic medical record) system. 


\section{International Advanced Research Journal in Science, Engineering and Technology}

Vol. 7, Issue 9, September 2020

\section{DOI 10.17148/IARJSET.2020.7910}

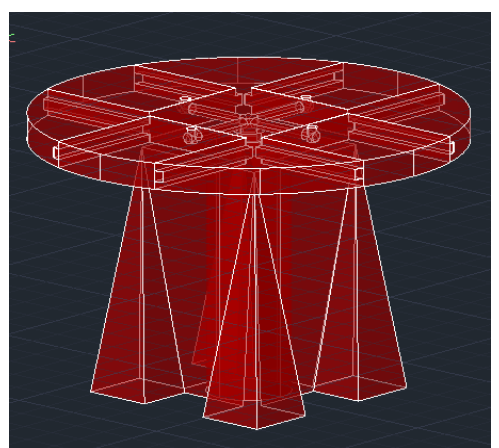

(a)

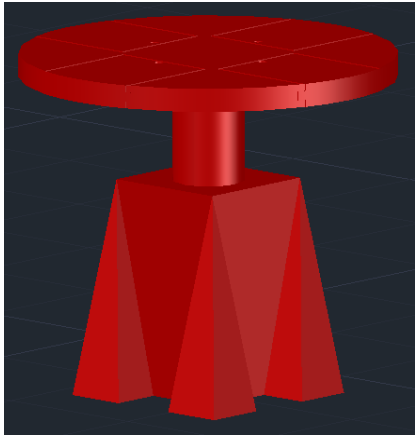

(c)

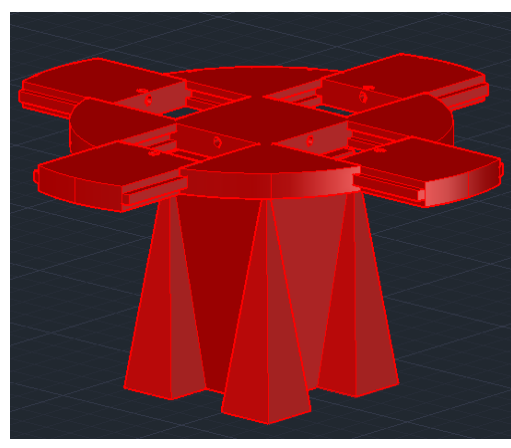

(b)

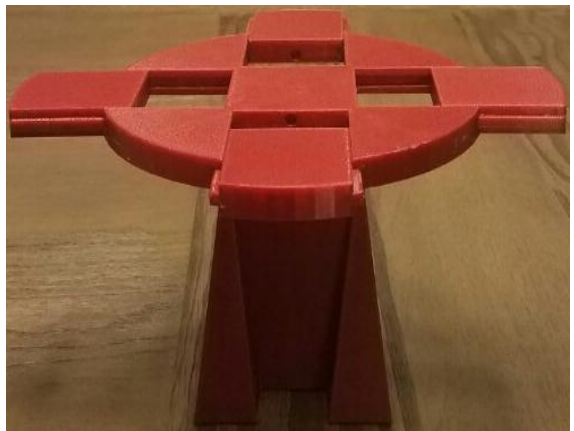

(d)

Fig. 6. Universal rotary table that will house up to four different exams: (a) x-ray view of table; (b) extended modules; (c) extended top; (d) 3D printed extended modules

\section{CONCLUSION}

Integrating 3D printing technology into the pre-engineering and physics course curricula made course lessons more interactive and sparked students' interest in these subjects. Students worked in a semester long to develop a design project from a computer design concept that was then $3 \mathrm{D}$ printed. These design projects are interesting and relevant approach to significantly enhance and deepen understanding of concepts in the science and pre-engineering courses. Most of the students who took part in this design projects had no or limited experience with both computer-aided design (CAD) modeling as well as 3D printing technology. But despite having limited prior experience, all student indicated a relatively high interest in learning more about 3D printing technology.

\section{REFERENCES}

[1]. M. Kinsler, C. McGill, G. Rodriguez, W. Berrios,, J. Chow, A. Enriquez, P. Grams,, X. Zhang,, H. Mahmoodi, W. Pong, and K. Siong The, 3D Printing as an Enabling Platform for Cross-Disciplinary Undergraduate Engineering Education and Research, Proceedings of the 2015 American Society for Engineering Education, Pacific Southwest Conference, San Diego, CA, 2015

[2]. N. Jaksic, New Inexpensive 3D Printers Open Doors to Novel Experiential Learning Practices in Engineering Education, 121 ${ }^{\text {st }}$ American Society of Engineering Education (ASEE) Annual Conference \& Exposition, Indianapolis, IN, 2014, Paper ID \#10642.

[3]. K. Meyers, B. P. Conner, \& A. S. Morgan, 3-D Printing in a First-Year Engineering Design Project, American Society of Engineering Education (ASEE) Annual Conference \& Exposition, New Orleans, Louisiana, 2016, 10.18260/p.26244

[4]. W. Johnson, C. Coates, P. Hager, N. Stevens, Employing Rapid Prototyping in a First-Year Engineering Graphics Course, American Society of Engineering Education (ASEE) Southeast Section Conference, 2009.

[5]. A. Sirinterlikci and S.F. Sirinterlikci, Utilizing Rep-Rap Machines in Engineering Curriculum, American Society of Engineering Education (ASEE) Annual Conference \& Exposition, Indianapolis, IN, 2014: p. 24.1354.1-24.1354.11

[6]. S. H. Ahn, M. Montero, D. Odell, S. Roundy, \& P. K. Wright), Anisotropic material properties of fused deposition modeling ABS, Rapid Prototyping Journal, 8(4), 2002, 248-257.

[7]. D. T. Pham \& R. S., Gault, A comparison of rapid prototyping technologies, Journal of Machine Tools \& Manufacture, 38(10), 1998, 1257-1287

[8]. E.P. Flynn, From Design to Prototype -Manufacturing STEM Integration in the Classroom and Laboratory, $1^{\text {st }}$ IEEE Integrated STEM Education Conference (ISEC), Ewing, NJ, 2011, pp. 3B1-3B4

[9]. E.P. Flynn, Design to Manufacture -Integrating STEM Principles for Advanced Manufacturing Education, $2^{\text {nd }}$ IEEE Integrated STEM Education Conference (ISEC), Ewing, NJ, 2012, pp. 1-4

[10]. O. Perez, M. Pitcher,, P. Espinoza,, H. Gomex,, H. Hemmitt,, R. Anaya,, P. Golding, and H. Nevarez, Analysis of the Impact of 3D Technology in STEM-Based Courses; Specifically Introduction to Engineering Courses, $122^{\text {nd }}$ American Society of Engineering Education (ASEE) Annual Conference \& Exposition, Seattle, WA, 2015.

[11]. A.Pikkarainen, A.Salminen, H.Piili, Creating learning environment connecting engg design \& 3D printing, Physics Procedia 89(2017), 122-130 